\title{
Review and Progress of China's Forest Continuous Inventory System
}

\author{
Guozhong Lin, Xiaorong Wen, Chunguo Zhou, Guanghui She* \\ College of Forest Resources and Environment, Nanjing Forestry University, Nanjing, China \\ Email: "njfulin@yahoo.com.cn
}

Received November 18 ${ }^{\text {th }}$, 2012; revised December 21 ${ }^{\text {st }}$, 2012; accepted December $29^{\text {th }}$, 2012

\begin{abstract}
China was one of the earliest countries to set up a system to continuously inventory natural forest resources. From the beginning of the 1970s until today, seven forest resource inventories have been carried out. This research summarizes the progress of forest continuous inventories and analyzes the existing deficiencies of China's forest continuous inventory system and forest management plan inventory. As stated above, this research offers corresponding countermeasures and suggestions: establishing a sample plot system for comprehensive national forest inventory and monitoring with each province's continuous forest inventory based on the foundation of the national sample plot system, able to develop the province as a subset of the overall province-level forest resource inventory according to the actual conditions in each province. Through annual multi-resource/multi-benefit surveying of the forests, the monitoring of forest amounts, quality, functions and benefits will be assisted in its entirety. The further integration of the forest continuous inventory and the forest management plan inventory is also discussed. This research also proposes the varied probability sampling method with sub-compartments as the basic sampling unit (or combinations of sub-compartments). This will also satisfy the requirements of ecological inventory by region.

Keywords: Review; China’s Forest Inventory System; Forest Continuous Inventory System; China Forest Resource
\end{abstract}

\section{Introduction}

Forest Inventory proceeds with relevant scientific methods and standards according to the needs of forest management, ecological environment construction, forestry production, scientific research and other factors. One of the important tasks of forest resource management is to collect, count, analyze and assess the data according to a defined scale of time and space, for forest resource distribution, amount, quality, and trends of development, as well as relevant natural and social economic factors (IUFRO, 1994).

The survey of forest resources carried out in order to understand the current situation of the forest resources and dynamic is known as Forest Continuous Inventory.

The Forest Continuous Inventory system includes the sampling method plot settings and survey index, time interval, and statistics and analysis etc. China's work on the forest inventory system actually took place after 1950 . It experienced 4 stages: 1 ) the initial establishing forest inventory system in nationwide in 1950s; 2) Sampling techniques using mathematical statistics as a theoretical basis from 1960s to1980s; 3) Remote sensing (RS), geographic information systems (GIS), global positioning system (GPS) technology was gradually introduced forest continuous inventory technology from 1990s to 2000s; 4) The expansion of inventory contents towards a multi-resource format includes forest productivity, biomass, carbon storage, etc. from 2000s to now.

The national inventory system only operates once every 5 years. Through the review of China's forest resource continuous inventory of progress, to further improve the perfecting

"Corresponding author. forest continuous inventory system, how to improve the efficiency of inventory expanded inventory results application, some useful advice put forward in this paper.

\section{China's Forest Inventory System and Its Course of Development}

\section{The Main Types of Forest Inventory}

The forest inventory system and its contents, methods, technology, form of results, etc. develop parallel to the rapid advance of information technology and the widespread use of mathematical statistics. These new technologies and techniques enable integration of the macro-requirements of national forestry construction and development with forestry production, and lead to the gradual establishment and perfection of management practice requirements (Xiao, 2005).

After nearly 60 years of development, China's large-scale forest continuous inventory took shape as a relatively perfect forest resource inventory system in view of the special characteristics and requirements of China's forestry development. According to the research goal, content, and technical methods, China's forest resource survey system can be divided into:

1) The nationwide forest inventory is referred to as a first class survey. Beginning in the 1970s, China's forest continuous inventory was gradually established at the province level (region, municipality), with the data from the provinces making up the main body of the overall forest Continuous inventory system. Every 5 years the inventory was repeated, using fixed sample plot surveys as the main method of carrying out regular monitoring. Within a unified time, and according to unified inventory requirements, a clear picture of the macroscopic 
situation of national forest resources and its succession of patterns was created. This provided scientific evidence for the forestry development strategy and adjustment of forestry policies in a timely and efficacious way. The national forest continuous inventory used a systematic sampling method, and the stratified sampling method was integrated into the sampling estimation. For the systematically extracted samples a stratified sampling estimation was completed according to forest volume or other survey factors, the principle being to make the factor variation as small as possible for all points within the layer and larger between the layers, in order to improve the accuracy of stratified sampling estimations. In addition, in order to improve the efficiency of sample plot extraction, double samples and double regression method estimates are frequently used. This takes advantage of easily measured auxiliary tree survey factors to realize estimates of forest accumulation. When the forest resource inventory also has other spatial data sources, such as aerial or satellite imaging, the multi-source data joint estimation method is usually still adopted.

2) The forest management plan inventory is referred to as a second class survey. The Forest Management Plan Inventory is one kind of forest resource inventory method. It uses stateowned forestry bureaus, nature preserves, forest parks and other areas of forest management units or administrative units above the county level as its departments, and is carried out with forest management sub-compartments as the basic unit. It is done once every 10 years, to provide evidence for the forest management plan, the overall plan and county-level or above forest planning, and the sub-compartment data files which take shape provide a data platform for forest management and tasks.

3) The forest task planning survey is known as a third class survey. This inventory is a carried out as a task-based survey with a particular scope or operational area as the basic unit. Usually it adopts the real measurement or sampling inventory method. For the forest resources in each operational area, site conditions and forest regeneration status are used to undertake a detailed survey, with the goal of satisfying the requirements of specific production tasks (e.g. afforestation, deforestation, forest tending etc.) arranged by basic level forestry production units, usually carried out in the production tasks of the previous year.

4) The annual special forest resource inventory is known as the verification survey. Its goal is to achieve a timely grasp of the situation regarding completion of the annual forestry production plan by forestry production units or project implementtation units. It evaluates the effectiveness of forestry production assignments, so that the Forestry Department and other related departments can adjust their annual production plan, to provide a basis to boost the effectiveness of carrying out the Forest Management Unit's forestry production plans. The verification inventory method usually takes a locality (city) or county (forestry bureau) as its basic units, using the terrain verification survey method.

5) Specialized inventory. Specialized forestry inventory includes site-type surveys, forest soil surveys, forest regeneration surveys, forest disease and pest surveys, preparation of forestry tables, forest growth surveys, forest multi-benefit measurement surveys and assessments, wild animal resource surveys, and other specialized inquiries. Its findings provide basic data directly to main specialized surveys, district, planning, design and establishment of forestry production.

\section{The Shape of the Forest Continuous Inventory System}

China's work on the forest inventory system actually took place after the founding of the new China, beginning in 1950 (Yi, 1991). At that time, forest inventory technology from the former Soviet Union was comprehensively introduced. The Soviet technology was in reality originally from Germany, and in addition the previous knowledge in the country on forest inventory came from European and Japanese systems, so China's technology was close to the European system from the beginning (Goran \& Hans, 1998; Kleinn et al., 1998; American Forest Council, 1992).

Table 1 shows the 4 stages of shape and progress of China's Forest Continuous Inventory.

In the early part of the 1950s, theodolites or compasses were principally used for measurement, and to regulate the survey area, using a grid method to divide the land into compartments and sub-compartments, set up banded standard plots, and measure each tree's diameter in the standard plot to calculate forest volume. Since the workload of the survey was too large, in the middle of the 1950s, aerial forest surveys were developed, along with aerial forest inventories and ground based comprehensive inventories. By the end of the 1950s, angle gauge measurement technology was also introduced (Scott, 1947; Ware \& Cunia, 1962), since the method was simple, accurate and reliable, and it received a wide range of applications throughout the country. According to the needs of that time, year after year the whole country was surveyed piece by piece. Since there were many investigation methods in different areas, survey quality was not consistent, and the scope of the inventory was incomplete. The statistical calculation methods were also rather poor at that time and remained so until the early 1960s. In 1962 the Forestry Department, responding to the requirements of forestry production development, organized the provinces (regions, city) to further the development of statistical work in the forest resource inventory across the whole country. For the 12year period from 1950 to 1962, all of the various forest resource survey data was systematized, statistically processed and finally brought into a nationwide summary.

During the 1960s, sampling techniques using mathematical statistics as a theoretical basis were introduced and large-scale experiments and measurement verification was organized. In terms of the survey's accuracy, quality, benefits and other aspects, remarkable results were achieved across the board. This laid the foundation for the sampling techniques we use in our forest inventories today.

In the 1970s, China began to explore a national forest continuous inventory system. This was due to the consideration

Table 1.

The 4 stages of shape and progress of China's Forest Continuous Inventory.

\begin{tabular}{llc}
\hline \multicolumn{1}{c}{ Stage } & \multicolumn{1}{c}{ Period } & Feature \\
\hline $\begin{array}{l}\text { Initial } \\
\text { establishment }\end{array}$ & 1950s & $\begin{array}{c}\text { theodolites or compasses, angle gauge } \\
\text { measurement }\end{array}$ \\
$\begin{array}{l}\text { Exploration \& } \\
\text { Shape }\end{array}$ & $\begin{array}{l}\text { 1960s to } \\
\text { 1980s }\end{array}$ & $\begin{array}{c}\text { sampling techniques, fixed sample plots at } \\
\text { 5-year intervals }\end{array}$ \\
$\begin{array}{l}\text { Development } \\
\text { 1990s to }\end{array}$ & RS, GIS, GPS technology application. \\
$\begin{array}{l}\text { Optimization \& } \\
\text { Expansion }\end{array}$ & $\begin{array}{l}\text { 2000s to } \\
\text { now }\end{array}$ & $\begin{array}{l}\text { multi-resource monitoring includes forest } \\
\text { productivity, biomass, carbon storage, etc. }\end{array}$ \\
\hline
\end{tabular}


that the former survey methods were all independent investigations and the results from before and after lack continuity and comparability. It was impossible to achieve precise information on trends of growth and decline of forest resources (Cunia \& Chevrou, 1969; Newton et al., 1974). In 1973, the Ministry of Agriculture and Forestry (MAF) arranged a national forest continuous inventory project in each province (region, city), developing the administrative districts and counties (bureaus) as basic units in the inventory system. This was the first time since the founding of the new China that a comprehensive forest continuous inventory was carried out in a relatively unified time scale and on a national scope (Taiwan temporarily excluded). In this inventory, through the establishment of a pilot program, the country's forest continuous inventory utilized systematic sampling methods and hierarchical regression estimate methods. Beginning in 1978, this system was fully developed in every province (region, city). The forest continuous inventory system is in accordance with the systematic sampling principle. Fixed sample plots were set up at ground level, the diameter of each tree in the standard plot was measured, and at 5-year intervals there was a review. This kind of inventory system can accurately obtain the current conditions of forest resources and uncover growth and decline trends. Regular patterns of resource development can be grasped, the effectiveness of resource management can be analyzed, and predictions of resource development trends can be predicted.

Thus China became one of the earliest countries to set up a forest continuous inventory system. From the 1970s until today, seven forest inventories have been carried out. The surveying period was divided into the years 1973-1976, 1977-1981, 19841988, 1989-1993, 1994-1998, 1999-2003, and 2004-2008. The 8th inventory is already underway.

The first country-wide forest inventory was the first forest continuous inventory with the counties (bureaus) as the basic units which reached a national scope (excluding Taiwan) since the founding of the People's Republic of China. Its main focus was on ascertaining the current forest resource conditions. Starting with the second national forest continuous inventory, the inventory system used the province (district, municipality) as the basic unit rather than the county. In subsequent inventories a review of previous inventory data, a gradual perfection of methods, and unceasingly enriched survey indices can be seen. At the end of the 1970s systematic sampling technology was first deployed, and by the 1990s remote sensing (RS), geographic information systems (GIS), global positioning system (GPS) technology was gradually introduced. Forest continuous inventory technology has shown continuous improvement. Before the 5th inventory, priority was given to timber production. For the most part, traditional ground level sampling was undertaken on the sample plots at this time. The 6th inventory increased forest ownership, plant disease and insect pest contents, and comprehensively introduced remote sensing technology, with $3 \mathrm{~S}$ technology as the foundation. It used remote sensory monitoring and ground surveying technology combined with the double stratified sampling remote monitoring system (Wang et al., 2007; Gregoire, 1993; Lyncii, 1995; Martin, 1982). At present, the 7th national forest continuous inventory has incorporated the forest's ecological functions, forest healthy class and biodiversity into the measurement categories as reflections of ecological status. The forest continuous inventory system is moving in the direction of development of a comprehensive monitoring system for both resources and ecological conditions (Xiao, 2005).

In the 1980s, China's forest continuous inventory system was further improved, unifying the technological system for the entire country. As information technology developed, remote sensing technology began to be used during surveying, and satellite imaging and aerial sample plot imaging also made their appearance. Within the statistical work of the inventory, unified survey factor coding and unified data storage formats came into usage. A complete statistical summary was entered into the computer system, guaranteeing the comparability and accuracy of survey results. This summary provides reliable basic data for the current national forest resource situation and its growth and decline status. In the area of sampling technology, an accurate two-stage and multi-stage estimation method for forest continuous inventory was proposed (The Forestry Department of the People's Republic of China, 1983).

Forest continuous inventories before the 1990s were mainly undertaken with the forest resources themselves as the focus. Beginning in the 1990s, the country began the development of the forest resource monitoring system. In 1991 the United Nations Food and Agricultural Organization provided China with aid projects in order to support the establishment of the monitoring system. Research was begun on the establishment of a national Forest Resource Monitoring Body. This period of forest resource inventory saw the beginning of widespread usage of 3S (remote sensing (RS), geographic information systems (GIS), the global positioning system (GPS)) technology, and improved investigative factors in the areas of forest ecology, health class, ownership and intensity of management (The Forestry Department of the People's Republic of China, 1994).

After the year 2000, China gradually established a forestry development strategy that gives priority to ecological construction. China's “Forest Continuous Inventory Technical Regulations” (The Forestry Department of the People's Republic of China, 2004; Arner et al., 2004; Cochran, 1997), issued in 2004, embody the survey indices of forestry development with a focus on ecological construction. Beginning with the 8th national forest resource inventory, the surveying system will gradually develop into a comprehensive monitoring system which will give equal priority to the forest resources and the ecological situation. There are 75 investigative factors for sample plots in the 8th inventory which can be divided into six aspects: land usage and coverage; site and soil; stand characteristics, forest function; ecological situation, and other forest land management related survey indices. At present the 8th national inventtory is underway, and the comprehensive monitoring system projects are divided into six projects and 133 monitoring factors (Ye et al., 2000): such as land cover and land usage, soil and site, land degradation, forest function efficiency, wood and other forest products, forest health conditions and disasters, and biomass and biological diversity.

\section{The Progress of Continuous Forest Resources Inventory}

Since the 1990s, China has carried out a series of optimization and improvement tasks on the current forest resource monitoring system. From 1993-1997, China received aid from the United Nations Development Program (UNDP) and other institutions and launched research on the "National Forest Resources Monitoring System”. In 1997 the original forestry department proposed a conception of a monitoring and assessment 
system for national forest resources and the environment, and the State Forestry Bureau Planning and Design Institute completed the overall design. In 1998, the compilation of the technological plan and regulations was completed. On December 12, 2004, research was initiated on establishing a framework for a comprehensive monitoring system for forest resources and the ecological situation (Bu, 2005). The general ideas and basic framework for such a system were put forth. The monitoring of water, air and soil at a microscopic level can accurately assess the status of forest resources and lead to the discovery of regular patterns of forest growth, and can also find the external factors influencing natural forest growth. This environmentallyfocused monitoring will represent a new direction of development for the comprehensive monitoring of forest resources, and also mirrors international development trends.

The characteristics of information on forest resources and ecological conditions come from many sources, and in many forms, shapes, grades and structures (Lie, 2006). Under the guiding idea of systemic integration, computer network technology, database technology, 3S technology, model simulation technology, and resources will be comprehensively integrated. Establishing a public service platform for comprehensive monitoring of forest resources, and promoting the further development, application and integration of information resource for forestry development and ecological construction to provide a real-time, dynamic, open information service will improve evaluation and forecasting ability to help avert disasters and ensure the success of engineering projects.

Remote sensing, aerial remote sensing, global positioning system, global information systems, database technology and computer network technology are widely applied in the modernization of forest resource monitoring. In particular, the use of remote radar sensing data to carry out local surveys, such as coastal shelter forest surveys, has been gradually increasing.

The expansion of inventory contents towards a multi-resource format includes forest productivity, biomass, carbon storage, forest products, temperate area resources, desertification, rocky desertification of soil resources and wild animal and plant resources. The development towards a multi-benefit format mainly includes investigation of the ecological conditions and functions of the forest, relating to sample plot biodiversity, forest health, and information output on ecological functions and forestry engineering effectiveness. Multi-resource, multibenefit monitoring will guarantee comprehensive monitoring of the forest volume, quality, functions and benefits.

In recent years, due to China's forest resource management requirements, each province hopes to have forest resource and ecological conditions information for every year. One key trend of variation in forest resource monitoring is how to use the 5year cycle of forest continuous inventories to realize annual forest resource monitoring. The method mainly used is to add detail to the original inventory sampling grid and review every year. Due to the heavy workload and high costs this method is not adopted by many. Another method is to utilize the data from the inventory, and carry out an update using the growth and consumption model. A third method is to correct and control the original inventory data through the use of remote sensing to provide annual data to combine with the original data (Roesch \& Reams, 1999; Reosch et al., 1993; Scott et al., 1999).

In 1999 Zhejiang province took the lead in performing an annual forest resource monitoring trial taking the requirements of the new situation into account. The method they adopted involves tightening the original forest inventory sampling grid and reviewing every year. Minor forest zones utilize modeling to update their data as an auxiliary method. Annual forest resource monitoring not only improves the usefulness of the results of the forest continuous inventory, but also provides annual forest resource data for resource management. Every year Zhejiang Province will make their annual monitoring of forest resources and ecological conditions into a public announcement, helping the society to understand the forest, and increasing public participation and enthusiasm for forestry.

\section{Discussion}

Modern forest inventory monitoring technology is not a single-source technology. Its development is also not an independent development of one branch of science. It is rather a comprehensive integration of many types of technology and even many different scientific fields (Zhu, 2001). At present, spatial remote sensing, aerial remote sensing, global positioning, global information systems, database technology and computer network technology, along with other high-technology products, have received different degrees of national usage in forestry (Wynne et al., 1999). Looking at each kind of technology in turn, it can be seen that ground surveying can't satisfy the needs of a macroscopic analysis; aerial digital imaging has too large an information content to be useful in the monitoring of forest resources over vast areas; and satellite monitoring can't satisfy the demands for level of detail needed in resource monitoring information. Therefore, as far as monitoring technology, it is necessary to organically combine ground surveying, aerial and satellite imaging as the information content, accuracy and time period requires. The technique of combining $3 S$ technology and ground survey methods, promoting space/ground/sky-integrated monitoring, receiving information from many channels and on many levels, can be an effective forest resource monitoring method.

The rapid growth of the national economy and the need for sustainable forestry development has given rise to some contradictions. On the one hand there is a requirement for the connotation of forest resource inventory to broaden, resource data to be updated year by year, and to develop forest resource monitoring in the direction of multi-resource comprehensive monitoring. On the other hand, although the establishment of a forest continuous inventory system played a very important role in promoting digital forestry and has become an important foundation for forest resource management, people have questioned the spending of such enormous sums of money to develop forest continuous inventories. How to further expand the sphere of application of the forest resource inventory results, and research low-cost continuous forest inventory methods remains a crucial research topic today.

China's forest continuous inventory system is set up so the provinces are the basic units providing data, with all of them using the systematic sampling method. Due to the limitations of that method, the results of monitoring only apply to the provinces, and break down into local municipalities. At the county level there is no guarantee of sampling precision. Another factor is that the national inventory system only operates once every 5 years, and in reality it is very hard to synchronize the inventory activities of the various provinces within that 5-year period. National statistics come with certain difficulties for the 
continuous forest resource inventory, and there is no way to utilize the forest inventory system to directly provide data on annual forest resource status and growth and decline status. To this end, some specialists have proposed surveying $1 / 5$ of the provincial sample plots every year, and leaving the remaining $4 / 5$ to use data updating methods to take the place of annual ground surveys. But what is urgently needed to solve this problem is 1) the basis for this statistical theory; 2) a method to extract $1 / 5$ of the sample plots and 3 ) a concrete method to update the data for the remaining $4 / 5$.

Moreover, the further integration of the forest continuous inventory and the second class (sub-compartment) forest resource inventory is also an important purpose of research in this paper. Under normal conditions, on the basis of the fixed sample plots usually used for the province level continuous inventory, the county level inventory sampling system can be established to act as a control on the sub-compartment survey precision. For this reason, realization of the data of the forest inventory can make the sub-compartment management more practical. The actual situation shows that costs and workload will be greatly increased by establishing such a system. Many counties have abandoned the increased-precision sample plot system that depends on county level data because it brings unavoidable problems of precision control in sub-compartment survey. At the same time, new requirements have been put forward for the progress of forest ecology monitoring which use mountain massif or even river basin areas (combined sub-compartments) as basic units. Some specialists (She, 1998; She et al., 2007) have proposed the varied probability sampling method with the county-level data making up the main body of data, and subcompartments as the basic sampling unit (or combinations of sub-compartments). This proposal is directed at the existing problems in second-class forest resource inventory, specifically in the south of China. With this type of sub-compartment sample plot a forest resource fixed angle gauge plot dynamic measurement system can be established in each province. At the same time, the statistical estimations of sub-compartment class sample plots can serve as a control on the precision of the entire second class forest (sub-compartment) inventory. This method not only uses the high efficiency of varied probability sampling established in the forest resource monitoring system, but also can combine the sampling estimation method with sub-compartment inventory. This will satisfy the requirements of ecological inventory by region. Sub-compartment class fixed sample plots can become a new forest resource monitoring system, according to the inventory being carried out.

First and second class forest resource inventories are both important components of the national and local forest resource monitoring system. The amount of sample plot data used in the nationwide province-based inventory estimates is rather large, and the corresponding workload and costs are prohibitive. On this basis it is suggested to establish a national forest continuous inventory system and sample plot monitoring system that takes the whole country as its basic unit. In this way, the amount of sample plots in each province can be greatly reduced, and also it will be beneficial to the development of an annual national forest inventory. At the same time the statistical data can control the precision of each province's own inventory data collection. Each province's continuous forest inventory can be implemented according to the method suggested above on a national sample plot basis according to the really existing conditions in the province, creating a more perfect forest resource monitoring system. The new forest continuous inventory system Put forward by this paper not only can play a role in originnal system but also can realize two classes of survey combination.

\section{REFERENCES}

American Forest Council (1992). Report of the blue ribbon panel on forest inventory and analysis. Washington DC: American Forest Council.

Arner, S. L., Westfall, J. A., \& Scott, C. T. (2004). Comparison of annual invertory designs using forest inventory and analysis data. Forest Science, 50, 188-203.

$\mathrm{Bu}, \mathrm{C}$. J. (2005). Research of the country's start of a framework for establishment of forestry resource and ecological condition comprehensive monitoring system. Journal of China Forestry Industry, 1, 4.

Cochran, W. G. (1997). Sampling techniques. Hoboken, NJ: John Wiley \& Sons, Inc.

Cunia, T., \& Chevrou, R. B. (1969). Sampling with partial replacement on three or more occasions. Forest Science, 15, 204-224.

Goran, K., \& Hans, T. (1998). The Swedish national forest inventory 1983-1987. Ultuna: Department of Forest Survey, Swedish University of Agricultural Sciences.

Gregoire, T. G. (1993). Estimation of forest growth from successive surveys. Forest Ecology and Management. 56, 267-278. doi:10.1016/0378-1127(93)90117-6

IUFRO, S4.02-05 (1994). International guidelines for forest monitoring. Vienna: IUFRO.

Kleinn, C., Dees, M., \& Polley (1998). Forest inventory and survey systems in Germany. Bonn: Federnal Ministry of Food, Agriculre and Forestry.

Lie, X. Y. (2006). Forestry resources and ecological condition information resource integration structure analysis. Journal of Forest Resources Management, 2, 51-56.

Lyncii, T. B. (1995). Compatible estimation of components of forest growth from remeasured point samples with restricted generalized least squares. Forest Science, 41, 611-628.

Martin, G. L. (1982). A method for estimating in growth on permanent horizontal points. Forest Science, 28, 111-114.

Newton, C. M., Cunia, T., \& Bickford, C. A. (1974). Multivariate estimators for sampling with partial replacement on two occasions. Forest Science, 20, 106-116.

Roesch, F. A., \& Reams, G. A. (1999). Analytical alternatives for annual inventory system. Journal of Forestry, 97, 33-37.

Roesch Jr., F. A., \& Deusen, P. C. (1993). Control variate estimators of survivor growth from point samples. Forest Science, 39, 66-77.

Scott, C. B. (1947). Permanent growth and mortality plots in half the time. Journal of Forestry, 45, 669-674.

Scott, C. T., Kohl, M., \& Schnellbacher, H. J. (1999). A comparison of periodic and annual forest surveys. Forest Science, 45, 433-451.

She, G. H. (1998). Study on the applied theory and method of angle measuring in volume growing estimation. Scientia Silvae Sinicae, 34, 25-30.

She, G. H., Lin, G. Z., Wen, X. R. et al (2007). Improvement of forestry resources second class survey methods and the establishment of angle sampling monitoring system. Journal of Nanjing Forestry University, 31, 11-14.

The Forestry Department of the People's Republic of China (1983). Main technical regulations of forest resources investigation. Beijing: China's Forestry Press.

The Forestry Department of the People's Republic of China (1994). Main technical regulations of forest resources survey. Beijing: China's Forestry Press.

The Forestry Department of the People's Republic of China (2004). Main technical regulations of continuously forest resources inventory. Beijing: China’s Forestry Press.

Ware, K. D., \& Cunia, T. (1962). Continuous forest inventory with partial replacement of samples. Forest Science Monographs, 3, 415422. 


\section{G. Z. LIN ET AL.}

Wang, Y. H., Xiao, W. F., \& Zhang, X. Y. (2007). Forest health monitoring and evaluation of the present situation and development trend domestically and abroad. Journal of Forestry Science, 43, 78-85.

Wynne, R. H., Oderwald, R. G., Reams, G. A., \& Scrivani, J. A. (1999). Optical remote sensing for forest area estimation. Journal of Forest, 98, 31-36.

Xiao, X. W. (2005). China forestry resources inventory. Beijing: China's Forestry Press.

Ye, R. H., Zhou, W. D., Huang, G. S. et al. (2000). A technical scheme for national forestry resources and the ecological environment comprehensive monitoring and system evaluation. Journal of Forest Resources Management, 3, 17-21.

Yi, H. Q. (1991). China's forestry survey planning and design history. Changsha: Hunan Press.

Zhu, S. L. (2001). The present situation and the future development characteristics of forest resources monitoring survey abroad. Journal of Forest Resources Management, 2, 21-26. 